\title{
Preventive Measures in the Tertiary Care of Spinal Cord Injured People*
}

Sir George Bedbrook, K.t., O.B.E., O.St.J., M.S. (Melb), Hon. M.D. (W.A.), Hon. F.R.C.S. (Ed.), Hon.D.Tech. (W.A.), F.R.C.S., F.R.A.C.S., D.P.R.M. (Syd), N. I. E. Beer, S.R.N. and R. K. McLaren, M.B. B.S. Royal Perth (Rehabilitation) Hospital, Western Australia

\section{Summary}

There are complications of spinal cord paralysis peculiar to the extended care period. These may be motor skeletal, neurogenic, visceral and psychogenic.

If practised regularly, prevention can be very effective in reducing the disability in all groups. Limb oedema, joint contractures, myasthenia and pain can be materially reduced by regular activity, maintaining joint mobility and the use of recreational motor skeletal activities.

Urinary tract infection and decubiti can be largely eliminated by careful attention to anti-bacterial suppression and better hygiene, both personal and at home. Decubiti can be eliminated by regular skin care and eliminating friction and pressure. Most episodes of such complications can be effectively prevented and treated by the expert home visiting nurse.

Social complications and drug abuse are areas of increasing concern. These can be kept to a minimum by regular assessment and, most importantly, when diagnosed early by the home visiting professional.

Key words: Spinal paralysis; Tertiary care; Complications (oedema, contractures, feet disorders); Prevention.

\section{Introduction}

The continued care of the spinal paralytic has not received great emphasis. After primary prevention has become effective in the next decades, and with a reduced incidence, tertiary complications will still occur. Over 89 per cent of people with spinal paralysis live in ordinary homes with modifications. Thus preventive measures become of paramount importance. 


\section{Complications in the community}

Some complications are peculiar to the extended care period. Recently Jousse (1982) tabulated these into four groups. More research about, and attention to these is needed.

Group 1

Motor Skeletal Pain

Charcot's Joints

Degenerative Disease

Low Back Pain

Chronic Limb Oedema

Haemorrhoids and Rectal Prolapse

Group 2

Bladder Dyssynergy

Urethral Obstruction

Contracted Bladder

Chronic Urinary Infection

Minor yet recurrent Decubiti

\author{
Group 3 \\ Syringomyelia \\ Sympathetic Dysreflexia \\ Pain of Cord Origin (late onset) \\ Group 4 \\ Increased mortality from: \\ Malignancy \\ Cardiovascular \\ Respiratory \\ Suicide \\ Burn Out \\ Psychological depression
}

Clearly not all of these complications can be overcome, due to the nature of paraplegia. However there are a number that can be prevented if their inevitability is realised and early care is instituted. Patients must be self-disciplined and be willing to carry out preventive care for years.

\section{Experience in Western Australia}

Over a long period of years the following have been considerably reduced in Perth, Western Australia, by the comprehensive service serving Western Australia.

Group 1

Limb Oedema

Joint contractures

Myasthenia

Pain
Group 3

Drug Abuse

Group 4

Social and Psychological problems

Respiratory problems

Group 2

Chronic Urinary Tract Infection

Decubiti

In the huge area of Australia's western state, with a well-established extended care service, some of these have received attention for long enough to record the results while others are only now being recognised. As has been known for some years, the Home Visiting Nurse is regularly the first person to detect complications in the tertiary period both actual and potential. 


\section{Group 1: Motor skeletal}

\section{a. Limb Oedema}

Lower limb oedema is commonest in spinal paralytics who are immobile-either by their own nature or because of gross handicap. Clinical investigation and even venograms are required to attempt to determine the pathological cause. Often a specific cause is difficult to determine. Factors which have been found useful in prevention are:

1. Elevation of limbs when and wherever possible.

2. Limitation of periods spent in the wheelchair to 4-6 hours.

3. Recreation taken in a posture with feet elevated. Urinary drainage is better when erect and supine-thus nocturnal diuresis is common.

4. Use of stocking supports, e.g., Zimmer Anti-Thrombosis supports. Carolon stockings are used as a routine in Australia. Summer climatic circumstances are important as heat increases oedema.

5. Mobility generally, including regular daily passive motion in the legelevated position. There is little doubt that general mobility is important in encouraging venous return and circulatory competence. A once or twice a day exercise activity to a fatigue situation is useful.

In the high temperatures of an Australian summer careful attention to change of posture and the above measures will reduce and even prevent major oedema. During summer in Australia many non-paraplegic people get some oedema which is correctable by the above regime. Preventive techniques are simple, repetitive and obtainable by patient action and must be considered as part of routine toilet procedures. With these measures gross chronic limb oedema is now only rarely seen-three cases in the past year.

Recently a group of 50 paraplegics and tetraplegics were examined at random in our Out Patient Department and Quadriplegic Centre. All had some oedema, but only two were actively trying to prevent it.

\section{b. Ankle and Feet Contractures}

Many spinal paralytics neglect their feet and are found to have no body image which includes their feet. Recently in the above group of 50, all had tight tendo achilles in the erect position while 16 of the 50 had toe contractions. The factors involved (and thus the preventive methods), can be stated:

1. Narrow footplates.

2. Not wearing shoes with firm soles.

3. Increase in calf spasm and ankle contracture.

4. Ceasing passive stretching of tendo achilles.

5. Failure of patients to use standing posture.

6. Nocturnal calf spasm leading to development of contractures.

These contractions have slowly become more common in Western Australia. The Royal Perth (Rehabilitation) Hospital Spinal Unit sees over 22 per year in the older patient needing surgical help. When present they call for myotomies, tendon elongation and occasional phalangeal surgery. Interestingly, this complication is not seen in the diligent or the sportsman. General measures which must be repeatedly stressed are:

1. Long term preventive measures. 
2. Education of patients, relatives and nursing staff.

3. Self-treatment and the development of a discipline of care. As indicated, in the group of 50 cases in the Quadriplegic Centre, 16 had such complications.

\section{c. Myasthenia in unaffected muscles}

This state is uncommon and even absent in the sportsman or sportswoman, and must be regarded as a disuse phenomenon unless there is developing a spaceoccupying lesion, such as syringomyelia. Daily resisted or isometric activity is essential as a preventive. This problem is more important than usually taught but is not the subject of this communication.

\section{d. Pain}

Pain is an increasing factor. While we all hope to make a specific pathological diagnosis prevention is so often forgotten (Bedbrook, 1981). In neurological problems such as stroke and spinal cord injury, pain can be reduced by:

1. Maintaining and encouraging activity while the primary cause of pain is treated.

2. Slowly ensuring that all synovial joints are fully mobile, e.g., shoulder.

3. Using local stimulation as counter-irritants.

4. Mobilisation of painful joints by movement (even manipulation), under a general anaesthetic when the pathology is static.

5. Intra-articular injection of suitable agents.

6. Increasing muscle power in a painless range of joint motion.

7. Discussing with the patient straight-forward reasons for primary pathology as well as for secondary causes.

8. Reducing all factors likely to aggravate the pain, from pure physical stress to specific psychological stress.

9. Introducing techniques of operant and reactive conditioning early in care (Mooney and Cairns, 1978) rather than as an end-of-line therapy.

10. Being flexible to use techniques such as: acupuncture, hypnosis, repeated joint injection, build-up exercises and vocational methods.

\section{e. Spinal Deformity}

Spinal deformity remains a major problem. Our experience to date has not shown us even $50 \%$ successful in preventive techniques. One of the authors (Bedbrook, 1969, 1973) has already reported on this subject.

Just as normal man changes so does spinal man who needs itinerant physical therapy or regular exercise in sports recreation to reduce both myasthenia and pain.

\section{Group 2: Visceral and decubiti}

\section{a. Urinary Tract Infections}

$\mathrm{Re}$-admission for urinary tract infections is not a major tertiary complication in 
Western Australia; however symptomatic urinary infections still occur within the community. Sterile midstream urines are collected in the home by the Home Visiting Nurse and treated with the appropriate antibiotic, after medical consultation. In 1982, of 51 suspected urinary tract infections, 42 actually required antibiotic treatment, while in 1983, of 82 cases, 71 required treatment.

Table 1 shows that this early detection and treatment results in a dramatically low re-admission rate to hospital for urinary tract infection.

Table 1. Re-admissions by home visiting service for treatment of urinary tract infection

\begin{tabular}{cccc}
\hline Year & $\begin{array}{c}\text { Patients } \\
\text { seen }\end{array}$ & $\begin{array}{c}\text { Patients } \\
\text { admitted }\end{array}$ & $\begin{array}{c}\text { Percentage of } \\
\text { those seen }\end{array}$ \\
\hline 1976 & 134 & 8 & $5.97^{\circ}{ }^{\circ}$ \\
1978 & 243 & 2 & $0.82^{\circ}{ }^{\circ}$ \\
1980 & 238 & 6 & $2.52^{\circ}{ }^{\circ}$ \\
1982 & 328 & 3 & $0.91^{\circ}{ }^{\circ}$ \\
\hline
\end{tabular}

Regular follow-up at the Urology Clinic, along with constant re-education in all bladder management techniques taught during the rehabilitative stage of the first admission to the spinal unit, helps maintain this low re-admission rate (Bedbrook, 1981).

\section{b. Decubiti}

Pressure sores still remain one of the major complications of paraplegia. However, through better education and access to people trained in spinal cord injuries, 77.8 per cent of all pressure sores are now successfully treated at home in Western Australia; of 464 pressure sores occurring from January 1980 to December 1983, 361 healed at home, only 103 patients were admitted.

Although total prevention of pressure sores has not occurred in this tertiary

Table 2 Patients with pressure sores readmitted by the home visiting service, January 1980-December 1983

\begin{tabular}{lr}
\hline Sacrum & 25 \\
Ischium & 20 \\
Heels & 16 \\
Pubic/Perineal & 12 \\
Malleoli & 10 \\
Toes & 7 \\
Trochanters & 4 \\
Elbows & 3 \\
Tibia & 2 \\
Miscellaneous & 4 \\
Total & 103 \\
\hline
\end{tabular}

Table 3 Pressure areas successfully treated at home by the home visiting service, January 1980-December 1983

\begin{tabular}{lr}
\hline Heels & 56 \\
Ischium & 53 \\
Malleoli & 42 \\
Sacrum & 36 \\
Toes & 33 \\
Pubic/Perineal & 23 \\
Trochanters & 19 \\
Tibia & 14 \\
Elbows & 14 \\
Knees & 12 \\
Spinous Process & 9 \\
Miscellaneous & 50 \\
$\quad$ non-specific pressure areas) & \\
Total & 361 \\
\hline
\end{tabular}

phase patients are now, through better education, seeking immediate help for minor areas which can be healed at home (Beer 1979). 
It is interesting to note that sores of the feet represent approximately one-third of those requiring hospitalisation and that many sores successfully treated at home are in this area. This supports the observation that feet are a very neglected area not only with oedema and foot drop as previously mentioned, but also with pressure sores (see Tables 2, 3).

The Rehabilitation Engineering Clinic, including a pressure unit, plays a major part in preventing tertiary decubiti. Noble (1981) has written extensively on this matter showing the scientific endeavour needed.

\section{Group 3: Ingested agents}

\section{a. Drug abuse}

Within Western Australia the use of 'hard drugs' among the spinal cord injured population is very rare. Only one drug-related death had been recorded resulting from addiction to Fortral leading to Pethidine and Morphia abuse. The Home Visiting Nurse must be aware of the abuse of prescribed drugs and drug interactions, such as alcohol taken with antibiotics, or muscle relaxants.

Close monitoring of medications is important, for example in one particular patient the long-term use of Indocid led to a perforated duodenal ulcer needing emergency surgery.

Constant blood level monitoring in the long-term use of antibiotics for osteomyleitis as well as levels of psychotic drugs such as lithium carbonate need regular monitoring. Preventing tertiary complications of drug-related disorders means a constant watch in the use of pharmaceuticals. Four cases have been encountered where chemical cystitis caused haematuria by the prolonged home use of ammonium chloride.

\section{b. Alcohol}

Alcohol plays a large part in drug abuse and has become a social problem. The pattern in the spinal cord injured is somewhat similar to that in the general population. Facts pertinent to the spinal cord injured include long periods of inactivity, loneliness or extreme desire to remain within their peer group. Alcohol is used as a psychological crutch to be able to live with their disabilities. Peripheral neuropathy due to long term abuse of alcohol has been encountered necessitating permanent residential care.

Alcohol abuse is encountered in over 50 per cent of people prior to spinal cord trauma. With high speeds in motor vehicles this abuse has emerged as a major contributing factor in the cause of many spinal cord injuries. Physical and social stress effects include marriage and family upheaval, vocational and financial disruption, and physical and psychological problems suffered by the alcohol abuser, his family, social and work acquaintances.

\section{Group 4: Community problems}

Chronic Social and Psychological Deprivation. This has not become a major problem in Western Australia because of the following factors: 
1. Regular visits by an itinerant nurse who watches for problems mainly in these areas (see Tables 4, 5).

2. Regular holidays and rest for patient and attendants made possible by community bodies.

3. Attention to income maintenance and social problems by social workers.

4. On-going education for all patients, relatives and staff.

5. Emergency admission to either the Spinal Unit or the Quadriplegic Centre in real cases of distress.

Delivery of equipment is a major responsibility for the nurse giving an opportunity to visit. It is during visits that many problems come to light. The statistics show that a number of patients are not home when visited (Tables 4, $5)$; this is because appointments are not regularly made in the metropolitan area. Thus the nurse sees the patient and care-givers in all situations when visited unexpectedly, and is therefore able to detect many problems. It must be emphasised that the home environment is the ideal situation to discuss problems, including those of a sexual nature. People feel less threatened and are much more at ease when in their own home and away from the busy Out Patient Clinics. After visiting homes for many months the nurse learns to recognise breakdowns in communications between families and can directly enquire into the most intimate problems.

Table 4 Reasons for visits by home visiting service, 1982

\begin{tabular}{lr}
\hline Social and Psychological & 928 \\
Equipment & 804 \\
Ward meetings & 258 \\
Patients not at home & 281 \\
Dressings & 201 \\
Mid Stream Urine Collection & 51 \\
Antibiotics for Urinary Tract Infection & 42 \\
Home modifications & 27 \\
Total Number of Visits (2 Registered Nurses) & 3,516 \\
\hline
\end{tabular}

Note: Discrepancy will be noted between total number of visits and total reasons for visits. This is because, over a two week period, several visits may be made for the same reason which is only recorded once.

Table 5 Reasons for visits by home visiting service, 1983

\begin{tabular}{lr} 
Social and Psychological & 1,009 \\
Equipment & 836 \\
Patients not at home & 245 \\
Dressings & 213 \\
Ward meetings & 196 \\
Mid Stream Urine Collection & 82 \\
Antibiotics for Urinary Tract Infections & 71 \\
Home modifications & 22 \\
Total Number of Visits (2 Registered Nurses) & 3,439 \\
\hline
\end{tabular}

Note: Discrepancy will be noted between total number of visits and total reasons for visits. This is because, over a two week period, several visits may be made for the same reason which is only recorded once. 
As Emerson said: 'The years teach much, which the days have never known'. Expert listening is frequently sufficient. Many people think they have to give advice or become a problem-solver in order to be useful. If problems are permitted to be expressed the paths to solutions often emerge by themselves.

Once a problem has been identified, discussion between the nurse and the Spinal Consultant is of the utmost importance (Bedbrook, 1981). The Consultant then sees the patient in the Out Patient Clinic and takes steps to prevent a small problem deteriorating to such a degree as to necessitate admission to hospital.

Major long-term complications of pressure sores and urinary tract infection have been reduced by 50 per cent by such measures as outlined (Noble, 1981). Expert long-term care has further reduced admission rate for complications by 50 per cent. This care is provided by: extended care Nurses, urologists, rehabilitation engineers, nursing staff, pressure clinic and home modifications schemes.

\section{Discussion}

It is possible to minimise the use of acute unit beds by long term patients with complications, as such complications can very often be prevented. Such admissions are unsatisfactory and uneconomical in every way. By applying major pathological and biological knowledge and then simple measures using scientific principles, even in the tertiary stage, the incidence can be considerably reduced so well as to make this whole area a major challenge (Bedbrook, 1981). By using such measures beds occupied in Western Australia have decreased from 40 in 1970 to an average of 30 in 1984, yet acute admissions remain unchanged.

Prevention of complications in great disability, including spinal paralysis, has a very wide spectrum of practice involving many diagnoses. The practice of such is an art based on science, as Sir William Osler said of Medicine overall. Roman and Greek attitudes to hopelessly-ill and deformed were not to care for them. It was not until Christian recordings of Christ healing the paralysed and the deformed that attitudes started to change and are now accepted almost wholly. I can only agree with Salter (1977) that we in the medical profession 'along with scientists, philosophers and theologians, have an obligation to play a leadership role in the affairs of mankind'. Prevention is an affair of mankind that can be achieved by an application of ALL disciplines in medicine-general medicine if you wish-no barriers or dissensions, for many measures, usually simple, will improve health, increase the quality of life and give us that precious commodity patients need of us-time.

Early interest, later disinterest, will keep the Cinderella of paraplegia and tetraplegia in the rags of disability. Francis Adams, a 19th century Hippocratic Scholar said,

'The great superiority of the ancient savants (the Hippocratists) over the modern, was that the former possessed a much greater talent for apprehending the general truth than the latter who confine their attention to particular facts and neglect too much the observations of general appearance'.

\section{Summary}

In Perth, Western Australia, the extended care of spinal cord injured persons has been vigorously persued. 
By regular, repetitive, well-defined activities such as home-visiting, regular clinical inspection, and education of patient and relatives many complications can be prevented. These complications include limb oedema, joint contractures, myasthenia of normal limbs, and pain. Most urinary tract infection and decubiti are preventible, as are social problems and drug abuse. Many minor complications can be treated at home.

\section{Résumé}

A Perth, capitale d'Australie occidentale, les soins prolongés des personnes à une moelle épinière blessée ont été vigoureusement recherchés.

Grâce à des activités régulières, répétitives et bien définies telles que des visites à domicile, des inspections régulières à la clinique, et l'enseignement aux patients et a leurs parents, beaucoup de complications peuvent être évitées. Ces complications comprennent les oedèmes des membres, les contractures des jointures, la myasthénie des membres normaux et la douleur. La plupart des contaminations de l'appareil urinaire et des decubiti peuvent être empêchées, ainsi que les problèmes sociaux et l'abus des narcotiques. Un grand nombre de complications mineures peuvent être traitées à domicile.

\section{Zusammenfassung}

In Perth, Westaustralien, wurde die erweiterte Pflege der Personen mit Rückenmarkverletzungen energisch fortgesetzt.

Mit regulären, wiederholten und klar festgesetzten Aktivitäten wie Hausbesuchen, regelmässigen klinischen Untersuchungen und Erziehung des Patienten und dessen Verwandten können viele Komplikationen verhindert werden. Diese Komplikationen umfassen Gliederödeme, Gelenkskontrakte, Myasthenie normaler Gliedmassen und Schmerzen. Dis meisten Infektionen der urinausscheidenden Organe und Dekubiti können verhindert werden; das gleiche gilt für soziale Probleme und den Missbrauch von Drogen. Viele kleinere Komplikationen können zu Hause behandelt werden.

\section{References}

BEDBROOK GM 1969 Intrinsic factors in the development of spinal deformities with paralysis. Paraplegia 6:222-232.

BEDBROOK GM, EDEBAM RC 1973 The study of spinal deformity in traumatic spinal paralysis. Paraplegia 10:321-335.

BEDBROOK GM 1981 1) The reduction of orthopaedic disability by rehabilitative methods.

2) Prevention of complications in orthopaedic disabilities. Journal of Rehabilitation in Australia. Published by Australian Council for Rehabilitation of Disabled.

BEER NIE 1979 Domicilliary visiting in Western Australia. Australian Nurses Journal 10:40-41.

Jousse A 1982 Editorial. Late complications of traumatic paraplegia. Paraplegia 20:18-19.

Mooney V, CaIRNS D 1978 Management in the patient with chronic low back pain. Orthopaedic Clinics of North America 9:543-548.

NOBLE P 1981 Prevention of pressure sores in spinal injury patients. World Rehabilitation Fund. Mimeograph No. 11.

SALTER RB 1977 Modern medicine genetics and the future of mankind. Hugh Smith Oration.

University of New South Wales, Australia. 